\title{
A unified interaction equation for strength and global stability of solid and hollow concrete-filled steel tube columns under room and elevated temperatures
}

\author{
Min $\mathrm{Yu}^{\mathrm{a}}$, Haoming $\mathrm{Xu}^{\mathrm{a}}$, Yin $\mathrm{Chi}^{\mathrm{a}}$, Jianqiao $\mathrm{Ye}^{\mathrm{a}, \mathrm{b},{ }^{*}}$ \\ a. School of Civil Engineering, Wuhan University, Wuhan 430072, China; \\ b. Department of Engineering, Lancaster University, Lancaster, LA1 4YR. UK;
}

\begin{abstract}
On the basis of plastic limit analysis, this paper proposes a novel, simple and unified interaction equation (N-M) for Concrete-filled Steel Tube (CFST) columns subjected to combined compression and bending. A unique feature of the new N-M equation is that the single equation is valid for a range of columns that can be solid, hollow, circular, polygonal, short or long. The single equation can also apply to columns under both room and elevated temperatures. Validations against independent laboratory test, analytical and numerical results are carried out to assess the accuracy and applicability of the equation. The new equation agrees well with most of the results used in the comparisons. It can be concluded that the simple and unified equation can be used in practical design with sufficient accuracy.
\end{abstract}

Keywords: Concrete-filled steel tube (CFST); Unified interaction formula; Combined load; Average temperature; Fire resistance

\section{Introduction}

Consideration of fire resistance is one of the most important design aspects in designing un-protected load bearing structural members, such as concrete filled steel tube (CFST) columns. On the basis of experiments and numerical simulations, various design formulas have been proposed in the last few decades for estimating fire resistance of CFST columns. The approaches to derive these formulas have great impact on their accuracy and applicability, as, in most cases, the formulas were developed from a numerical fitting process through parametric regression.

CFST columns are normally designed for supporting axial compression. However, a CFST column may also support significant bending caused by uneven distribution of stresses over its cross-section. Extensive research has been carried out mainly for columns subjected to compression, as briefly reviewed below.

Design formulas for calculating load bearing capacity and fire resistance time of CFST columns were developed on the basis of experimental and numerical studies by, e.g., Kodur ${ }^{[1-3]}$ who conducted extensive parametric analysis and proposed formulas for estimating fire resistance time of solid circular and square CFST columns under axial load. Using Eurocode $4^{[4]}$, Wang and Kodur ${ }^{[5]}$ developed an approach for evaluating squash load and rigidity of solid CFST columns at elevated temperature. Li et al. ${ }^{[6]}$ proposed a formula for calculating bearing capacity of solid circular CFST columns under fire on the basis of parametric analysis and regression; Han et al. ${ }^{[7,8]}$ calculated strength index of circular and rectangular solid CFST columns based on the results of parametric and experimental studies, and proposed also a formula for calculating thickness of fireproof materials. Tan and Tang ${ }^{[9]}$ applied Rankine method to analyze reinforced and plain solid CFST columns at elevated temperature; Using an average temperature approach, Yu et al. ${ }^{[10]}$ proposed a unified approach for calculating fire resistance of solid and hollow CFST columns having circular and polygonal cross sections; Espinos et al. ${ }^{[11}$, ${ }^{12]}$ presented a simple calculation method for evaluating fire resistance of circular and elliptical solid CFST columns under axial load based on Eurocode $4^{[4]}$, where the concept of equivalent temperature was adopted. He and Zhong ${ }^{[13]}$ used finite element analysis to calculate thickness of fireproof materials of CFST columns. Yin 
and $\mathrm{Zha}^{[14]}$ adopted the limit analysis method in the study of fire performance of CFST columns under axial load; and Chung et al. ${ }^{[15]}$ used a similar numerical method in the study of fire performance of square CFST columns under eccentric compression.

From the above review and to the authors' best knowledge, the current calculation formulas were all developed individually for specific section profiles and separate sets of design equations have to be used for columns subjected to room and elevated temperatures. These formulas are normally lengthy and complex, requiring introduction of many modification factors from empirical studies. In this paper, a much simple design formula is proposed for plastic limit analysis of solid and hollow CFST columns that can be circular and polygonal and are subjected to combined axial compression, bending and elevated temperature. We first present the N-M interaction curves of various CFST sections by the limit analysis method, from which a unified N-M equation for short CFST columns under combined loads is proposed and verified by comparing with the numerical results from full plastic limit analyses. After considering the effect of initial imperfections and global instability, the formula is extended to study long CFST columns under room temperature. The N-M interaction curves of long CFST columns are obtained next and compared with those from existing design formulas, independent numerical calculations and available experimental results. Finally, a unified calculation formula that is applicable to both long and short CFST columns under normal and elevated temperatures is developed on the basis of the average temperature approach.

\section{Unified N-M interaction equation of short CFST columns under combined axial and bending loads}

\section{1 limit analysis method for calculating fire resistance of CFST}

At the limit state, the steel tube is fully yielded and the concrete in compression reaches its strength limit. As adopted in Eurocode $4^{[4]}$, it is assumed that the steel and concrete interactions and the tensile strength of the concrete are negligible. Therefore, they will not be considered in the calculations throughout this paper.

Assuming that a CFST is subjected to ISO-834 standard fire. The temperature field of the CFST is nonuniform and time dependent, which can be calculated from a heat transfer analysis by using COMSOL Multiphysics. More details of the heat transfer model for CFST columns in fire are described in Wang et al. ${ }^{[16]}$ and $\mathrm{Yu}$ et al. ${ }^{[17]}$, which were validated by experimental results. The temperature dependent material properties can be taken from Eurocode $4^{[4]}$ or Lie ${ }^{[18]}$, the latter has been adopted by Chinese Design Codes ${ }^{[19]}$ (GB 509362014). For the cross section shown in Fig.1, at a given time instance, the ultimate axial force, $N_{\mathrm{T}}$, and the ultimate moment, $M_{\mathrm{T}}$, can be calculated, respectively, as

$$
\begin{aligned}
& N_{T}=\iint_{A_{c, c}} f_{c k, x, y, T} d A+\iint_{A_{s, c}} f_{s, x, y, T} d A-\iint_{A_{s, t}} f_{s, x, y, T} d A \\
& M_{T}=\iint_{A_{c, c}} y \cdot f_{c k, x, y, T} d A+2 \iint_{A_{s, c}} y \cdot f_{s, x, y, T} d A
\end{aligned}
$$

where the moment, $M_{T}$, is taken about the $x$-axis; $A_{s}, A_{s, c}$ and $A_{s, t}$ denote the total area, the area in compression and the area in tension of the steel, respectively; $A_{c}, A_{c, c}, A_{c, t}$ and $A_{k}$ are the respective total area, area in compression, area in tension and hollow area of the concrete; $f_{s, x, y, T}$ and $f_{c, x, y, T}$ are, respectively, the strength of steel and concrete at location $(x, y)$ where temperature is $T$. 


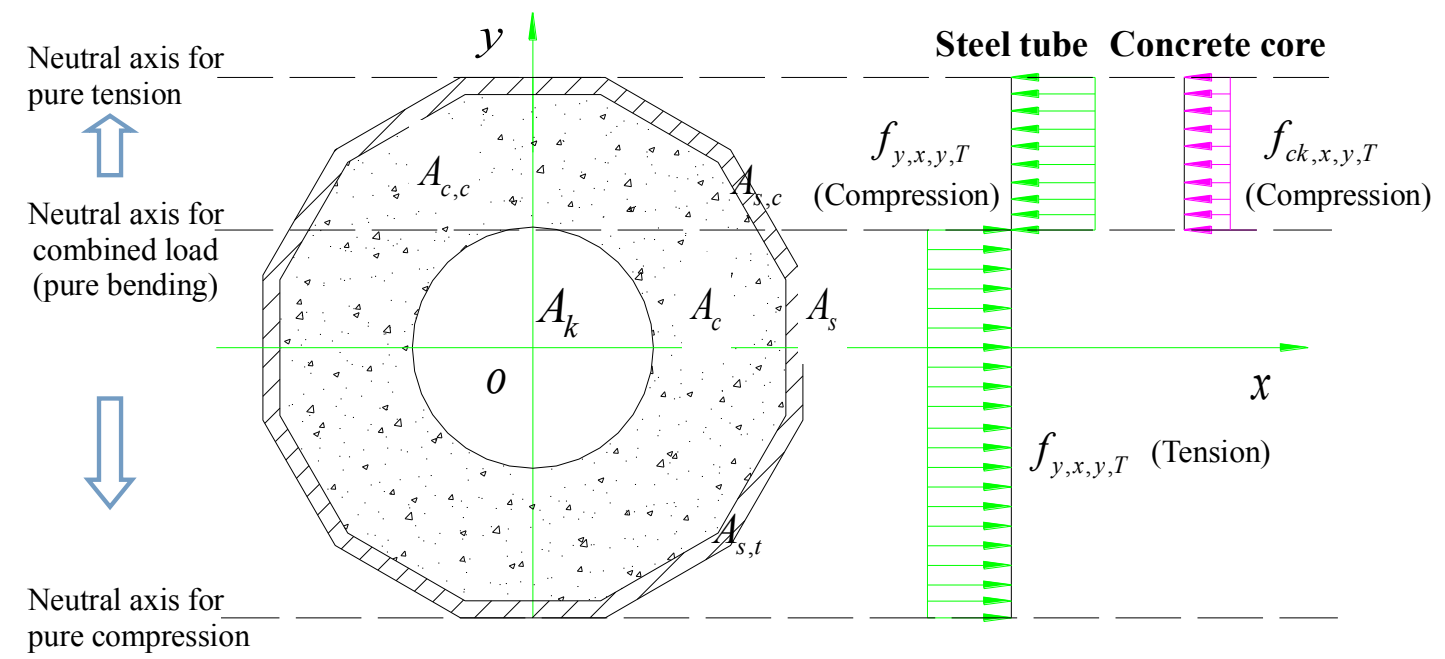

Figure 1 CFST section under fire subject to compression and bending

Eqs.(1) and (2) can be used to describe three ultimate loading cases, including: (a) $\mathrm{M}_{\mathrm{T}}=0$ and $\mathrm{N}_{\mathrm{T}}<0$, i.e., the column is subjected to uniaxial tension; (b) $\mathrm{M}_{\mathrm{T}}=0$ and $\mathrm{N}_{\mathrm{T}}>0$, i.e., the column is subjected to uniaxial compression; and (c) $\mathrm{M}_{\mathrm{T}} \neq 0$ and $\mathrm{N}_{\mathrm{T}}=0$, i.e., the column is subjected to pure bending. Thus, the load bearing capacities calculated from these three cases are, respectively, tensile bearing capacity, compressive bearing capacity and bending bearing capacity.

\subsection{Calculation of N-M interaction curves}

Consider first a series of circular CFST columns with different section profiles. The diameter of the steel tube, $D$, is from 200 to $1200 \mathrm{~mm}$; the thickness of the steel tube, $t$, is from $3 \mathrm{~mm}$ to $18 \mathrm{~mm}$. The hollow ratio of the section $\psi$, which is defined as the ratio of the central hollow area and the total area enclosed by the outside boundary of the section, i.e., $\psi=A_{k} /\left(A_{c}+A_{k}\right)$, is from 0.0 to 0.65 , the grade of steel ranges from Q235 to Q460 and the concrete are the commonly-used $\mathrm{C} 30$ to $\mathrm{C} 80$, where the numbers after $\mathrm{C}$ denote cube compressive strength of the concrete, $f_{\mathrm{cu}}$, in MPa. For octagonal and square CFST columns, the non-circular sections are transformed to their equivalent circular sections having the same cross-sectional areas as their respective noncircular originals. The transformation is based on an equivalence approach that has been successfully used previously in similar applications by the authors ${ }^{[20]}$. Table 1 presents six chosen values for each of the five design parameters within the ranges described above. Since considering a full combination of all possible designs in Table 1 requires extensive computational effort, the uniform design experimentation method is used to select representative designs from Table 1 for calculations. Thus, the number of designs to be calculated is reduced from the combinations shown in Table 1 to those shown in Table 2. In Tables $1, f_{\mathrm{y}}$ is yield strength of steel and $f_{\mathrm{c}}$ ' denotes characteristic value of cylinder compressive strength of concrete, which can be converted from $f_{\mathrm{cu}}$, i.e., $f_{\mathrm{c}}^{\prime}=0.8 f_{\mathrm{cu}}{ }^{[21]}$.

Table 1 The design parameters of CFST sections under fire

\begin{tabular}{lcccccc}
\hline \multirow{2}{*}{ Design parameters } & \multicolumn{7}{c}{ Options } \\
\cline { 2 - 7 } & 1 & 2 & 3 & 4 & 5 & 6 \\
\hline Equivalent diameter $(\bar{D} / \mathrm{mm})$ & 200 & 400 & 600 & 800 & 1000 & 1200 \\
Equivalent thickness $(\bar{t} / \mathrm{mm})$ & 3 & 6 & 9 & 12 & 15 & 18 \\
Hollow ratio $\psi=A_{k} /\left(A_{c}+A_{k}\right)$ & 0 & 0.25 & 0.35 & 0.45 & 0.55 & 0.65 \\
Steel grade $\left(f_{\mathrm{y}} / \mathrm{MPa}\right)$ & $\mathrm{Q} 235$ & $\mathrm{Q} 295$ & $\mathrm{Q} 345$ & $\mathrm{Q} 390$ & $\mathrm{Q} 420$ & $\mathrm{Q} 460$ \\
\hline
\end{tabular}




\begin{tabular}{lcccccc}
\hline & $(235)$ & $(295)$ & $(345)$ & $(390)$ & $(420)$ & $(460)$ \\
Concrete grade $\left(f_{\mathrm{c}}^{\prime} / \mathrm{MPa}\right)$ & $\mathrm{C} 30$ & $\mathrm{C} 40$ & $\mathrm{C} 50$ & $\mathrm{C} 60$ & $\mathrm{C} 70$ & $\mathrm{C} 80$ \\
& $(24)$ & $(32)$ & $(40)$ & $(48)$ & $(56)$ & $(64)$ \\
\hline
\end{tabular}

Table 2 Uniform design table for 5 factors and 6 levels with 6 runs

\begin{tabular}{cccccc}
\hline \multirow{2}{*}{$\begin{array}{c}\text { Column } \\
\text { number }\end{array}$} & \multicolumn{4}{c}{ Optimally selected values of the parameters from the options in Table 1 } \\
\cline { 2 - 6 } & $\begin{array}{c}\text { Equivalent diameter } \\
\text { of steel tube }\end{array}$ & $\begin{array}{c}\text { Equivalent thickness } \\
\text { of steel tube } \bar{t}\end{array}$ & $\begin{array}{c}\text { Hollow } \\
\text { ration } \psi\end{array}$ & Steel grade & $\begin{array}{c}\text { Concrete } \\
\text { grade }\end{array}$ \\
\hline 1 & $200 \mathrm{~mm}$ & $9 \mathrm{~mm}$ & 0.00 & Q390 & C40 \\
2 & $400 \mathrm{~mm}$ & $18 \mathrm{~mm}$ & 0.45 & Q345 & C80 \\
3 & $600 \mathrm{~mm}$ & $3 \mathrm{~mm}$ & 0.65 & $\mathrm{Q} 420$ & $\mathrm{C} 60$ \\
4 & $800 \mathrm{~mm}$ & $12 \mathrm{~mm}$ & 0.55 & $\mathrm{Q} 235$ & $\mathrm{C} 30$ \\
5 & $1000 \mathrm{~mm}$ & $6 \mathrm{~mm}$ & 0.25 & $\mathrm{Q} 295$ & $\mathrm{C} 70$ \\
6 & $1200 \mathrm{~mm}$ & $15 \mathrm{~mm}$ & 0.35 & $\mathrm{Q} 460$ & $\mathrm{C} 50$ \\
\hline
\end{tabular}

It is assumed that the columns are subjected a combined axial compression and bending under elevated temperature. Applying equations (1) and (2) repeatedly for all the possible combinations listed in Table 2 for every 10 minutes intervals up to 4 hours, the ultimate bending moment, tension and compression of all the cases are obtained, from which the N-M curves of the columns are plotted. To save space and without loss of generality, Figs 2, 3 and 4 show the curves of selected columns specified in Table 2 for solid (No. 1) and hollow (No. 6) columns having circular, square and octagonal sections. Equivalent diameter $\bar{D}$ and thickness $\bar{t}$ are used when the sections are not circular.

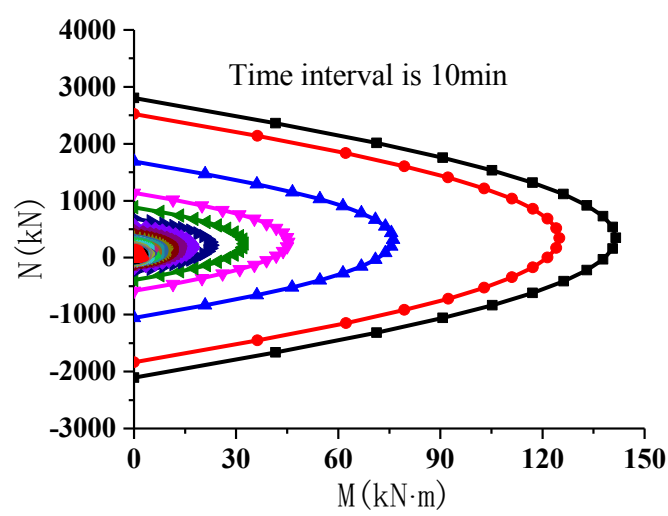

a) No.1 (Solid)

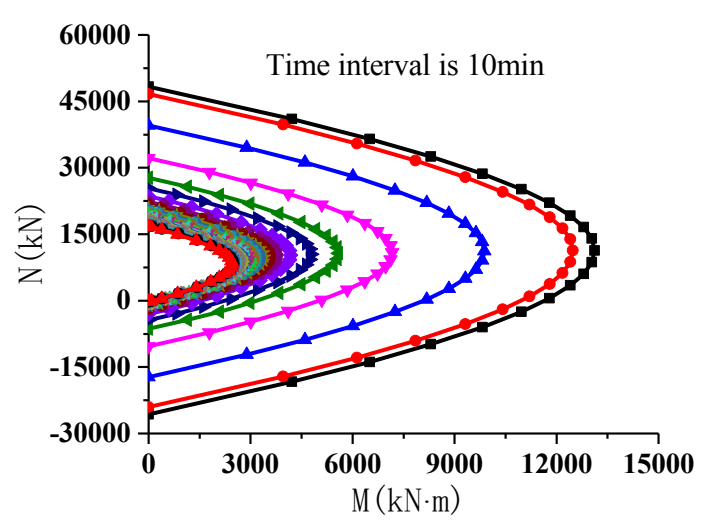

b) No. 6 (Hollow)

Figure 2 Calculation results of the N-M interaction curve for circle-CFST

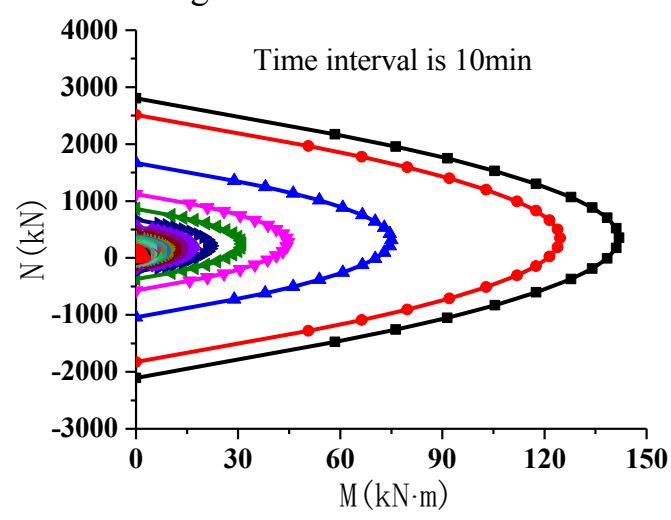

a) No.1 (Solid)

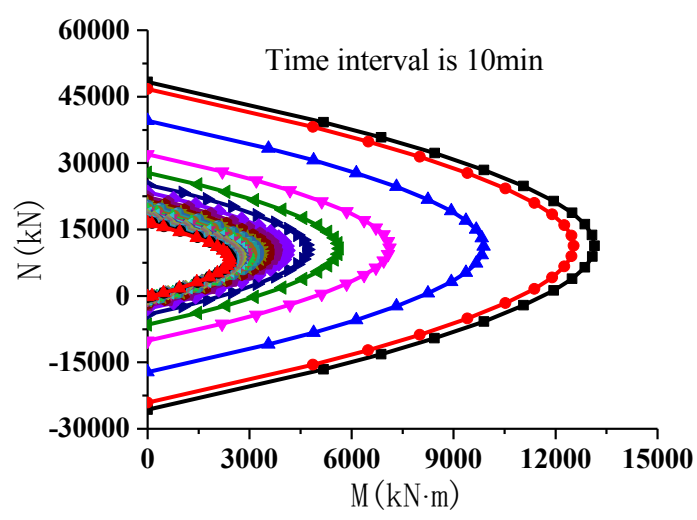

b) No. 6 (Hollow) 
Figure 3 Calculation results of the N-M interaction curve for octagonal-CFST

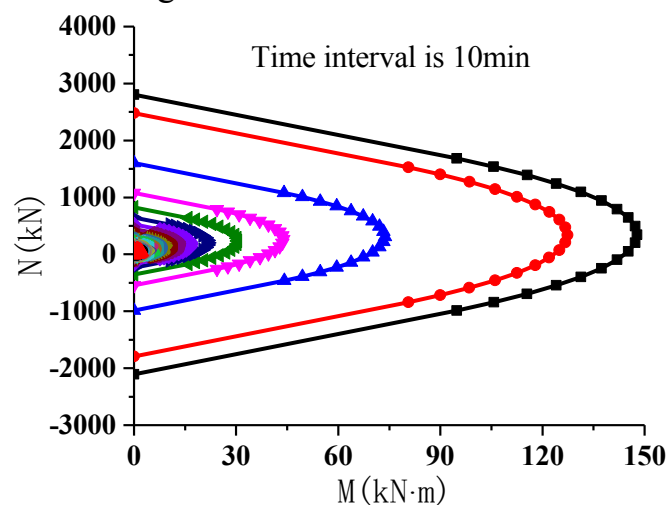

a) No.1 (Solid)

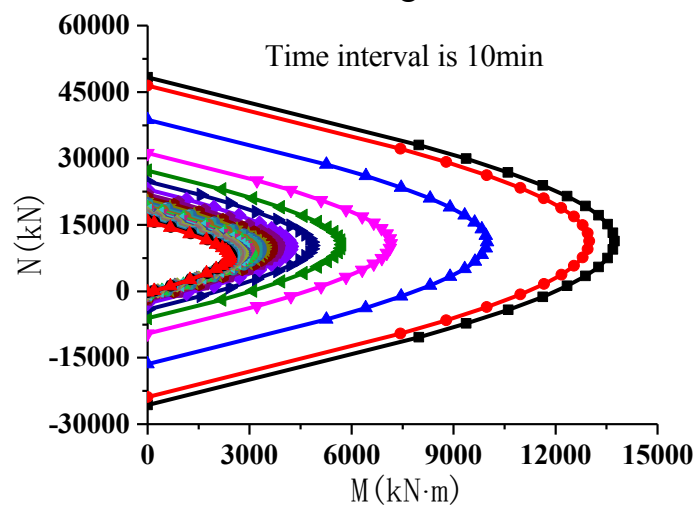

b) No. 6 (Hollow)

Figure 4 Calculation results of the N-M interaction curve for square-CFST

In the above figures, the outmost curves (black) are the N-M curves of the respective columns under room temperature. The curves are plotted then at 10 minutes intervals, from the right to left, until 240 minutes fire exposure time is reached. It is evident from the figures that all the curves follow a similar pattern that may be defined approximately by a mathematical equation. It is worth noting that the curves in the above figures are calculated by using the material properties provided by Eurocode $4^{[4]}$. The calculated N-M curves using Lie's ${ }^{[18]}$ material model, which are not presented here, showed the same pattern.

\subsection{Unified N-M interaction equation and validation}

It has been observed that the N-M interaction curves shown in Figs 2-4, though for different columns subject to different temperature, are geometrically similar, and may be approximately represented by a quadratic equation of $\mathrm{M}$ and $\mathrm{N}$. Thus, from the observation, we assume that (a) all N-M interaction curves can be defined by a quadratic equation; and (b) the curves always pass through points $\left(M_{u, T}, 0\right),\left(0, N_{0, T}\right)$ and $\left(0, N_{0 t, T}\right)$, representing, respectively, the three special ultimate loading cases mentioned in Section (2.1). Hence, we propose the following simple N-M interaction equation applicable to both normal and elevated temperature.

$$
\frac{M}{M_{u, T}}=\left(1-\frac{N}{N_{0, T}}\right)\left(1-\frac{N}{N_{0 t, T}}\right)
$$

where $N, M \longrightarrow$ axial force and bending moment on a section, where compression is defined as positive

$N_{0 . T} \longrightarrow$ ultimate compressive strength (positive)

$N_{0 t . T}$ ultimate tensile strength (negative)

$M_{u, T} \longrightarrow$ ultimate bending moment.

To verify the accuracy of equation (3) in representing the N-M interaction curves calculated from Eqs. (1) and (2), we include all the results shown in Fig.2 and those from Eqs. (1) and (2) for the design combinations in Table 2 by plotting $X=M / M_{u, T}$ against $Y=\left(1-N / N_{0, T}\right)\left(1-N / N_{0 t, T}\right)$ in Fig.5, respectively, for the circular, square and octagonal sections. 


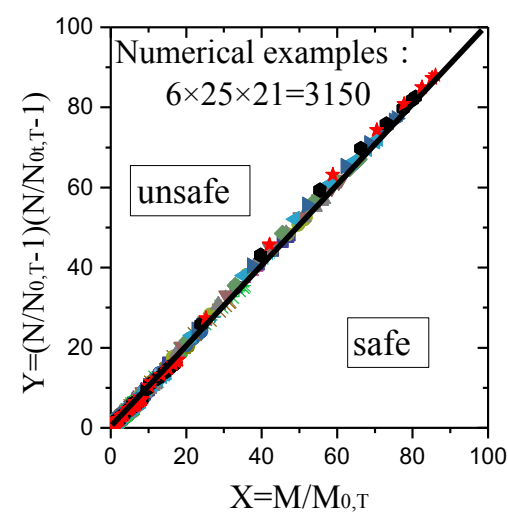

a) circle-CFST

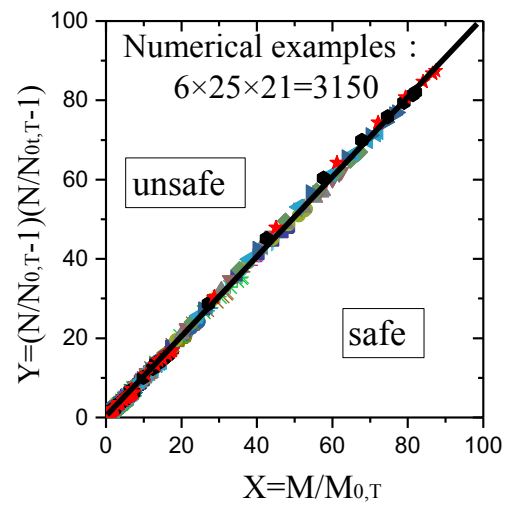

b) octagonal-CFST

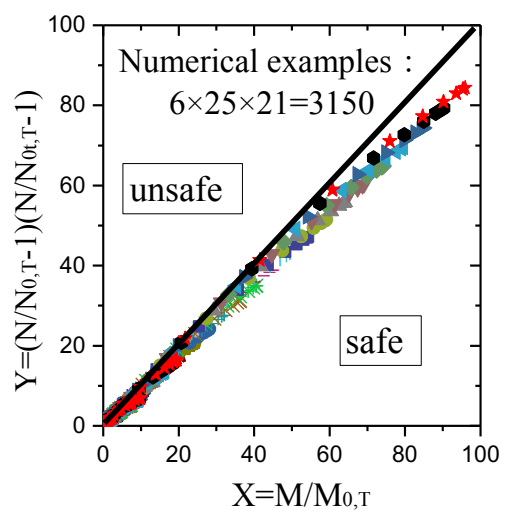

c) square-CFST

Figure 5 Verification of the unified N-M interaction equation of CFST under fire

In each of the figures (a-c), a total of 3150 points are plotted, which are calculated from the combination of the 6 uniform designs shown in Table 2, at every 10 minutes intervals up to 4 hours and the 21 points used in constructing each of curves in Figures 2-4. It is clear from Fig.5 that almost all the data are concentrated along the line $\mathrm{X}=\mathrm{Y}$, which means that the results calculated from Eqs. (1) and (2) for all the sections studied in Section 2.2 agree well the simple Eq.(3), though the results from the square sections are slightly less satisfactory due to its small number of sides. In other words, Eq.(3) can be used as the N-M interaction equation for both circular and polygonal CFST sections subjected to room and elevated temperatures.

\section{Unified N-M interaction equation and global stability of long columns}

\subsection{N-M interaction equation of long columns under room temperature}

For a pin supported long column having a mid-height deflection $v_{m}$ caused by a transverse load, the deflection will further increase if an axial compressive force, $\mathrm{N}$, is applied at the ends. From elastic buckling analysis, the final mid-span deflection is ${ }^{[22]}$

$$
v_{\max }=\frac{v_{\mathrm{m}}}{1-N / N_{\text {cr }}}
$$

where $N_{\text {cr }}$ is the critical bucking load of the column. Thus, the mid-span bending moment is ${ }^{[22]}$ :

$$
\begin{aligned}
M_{\max } & =M+N v_{\text {max }}=M+\frac{N v_{\mathrm{m}}}{1-N / N_{\mathrm{cr}}} \\
& =\frac{M}{1-N / N_{\mathrm{cr}}}\left[1+\left(\frac{N_{c r} v_{\mathrm{m}}}{M}-1\right) \frac{N}{N_{\mathrm{cr}}}\right]=\frac{\beta_{m} M}{1-N / N_{\mathrm{cr}}}
\end{aligned}
$$

where $M$ is the moment caused by the transverse loading; $\beta_{m}$ is called coefficient of equivalent bending moment, the value of which is normally taken from design codes in practical design ${ }^{[23]}$.

If initial imperfections are considered, which produce an additional deflection $v_{0}$, the N-M interaction equation considering axial compression, bending and imperfection can be written as

$$
\frac{\beta_{m} M+N v_{0}}{M_{u}\left(1-N / N_{\text {cr }}\right)}=\left(1-\frac{N}{N_{0}}\right)\left(1-\frac{N}{N_{0 t}}\right)
$$

after considering Eqs.(3) and (5), where the coefficient of equivalent bending moment due to imperfections is assumed to be unit, as recommended by EN 1994-1-1:2004 ${ }^{[23]}$. 
when $M=0$ in Eq.(6), $N$ represents the critical buckling load of the column with initial imperfection, $\varphi_{s c} N_{0}$, where $\varphi_{s c}$ is the stability factor. Solving $v_{0}$ from Eq.(6) yields

$$
v_{0}=\frac{M_{u}\left(1-\varphi_{s c}\right)\left(1-\varphi_{s c} N_{0} / N_{0 t}\right)\left(1-\varphi_{s c} N_{0} / N_{c r}\right)}{\varphi_{s c} N_{0}}
$$

Substitution of Eq.(7) into Eq.(6) yields the following N-M interaction equation of long CFST columns under room temperature

$$
\frac{\beta_{m} M}{M_{u}}=\left(1-\frac{N}{N_{0}}\right)\left(1-\frac{N}{N_{0 t}}\right)\left(1-\frac{N}{N_{\text {cr }}}\right)-\frac{N\left(1-\varphi_{s c}\right)\left(1-\varphi_{s c} N_{0} / N_{0 t}\right)\left(1-\varphi_{s c} N_{0} / N_{c r}\right)}{\varphi_{s c} N_{0}}
$$

Equation (8) is complex and is not convenient for practical design applications. On the basis of the experience gained from the construction of Eq.(3) and the structure of Eq.(8), we assume that the N-M interaction equation of long CFST columns under room temperature takes the following simple form,

$$
\frac{\beta_{m} M}{M_{u}}=\left(1-\frac{N}{\varphi_{s c} N_{0}}\right)\left(1-\frac{\varphi_{s c} N}{N_{0 t}}\right)\left(1-\frac{\varphi_{s c} N}{N_{\text {cr }}}\right)
$$

To estimate the accuracy of Eq.(9) in comparison with Eq.(8), we compared the N-M interaction curves based on the calculations using Eqs.(8) and (9) for a range of slenderness ratios. The curves were also compared with those from independent calculations by Han ${ }^{[24,25]}$, as shown in Figs.6 and 7. From the figures, the N-M interaction curves from all the approaches have a reasonable good agreement. When the slenderness ratio $\lambda<40$, Eq.(9) is virtually identical to Eq.(8), while when the slenderness ratio is greater, the results from the two equations show some discrepancies, though they are not significant. Detailed comparisons have shown that the average difference between Eq.(9) and Eq.(8) is within 5.0\%. However From the comparisons, it can be seen that Eq.(9) provides a more conservative design equation than Eq.(8) and the interaction curves are closer to the ones from Han' ${ }^{[24,25]}$ numerical calculations than from the formulas proposed by the same authors.

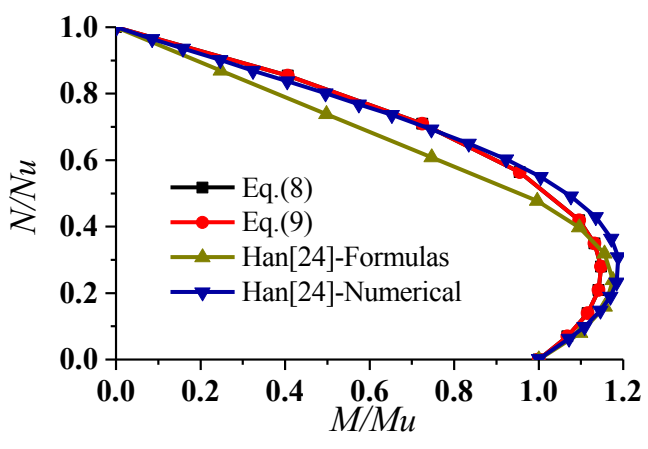

a) $\lambda=10$

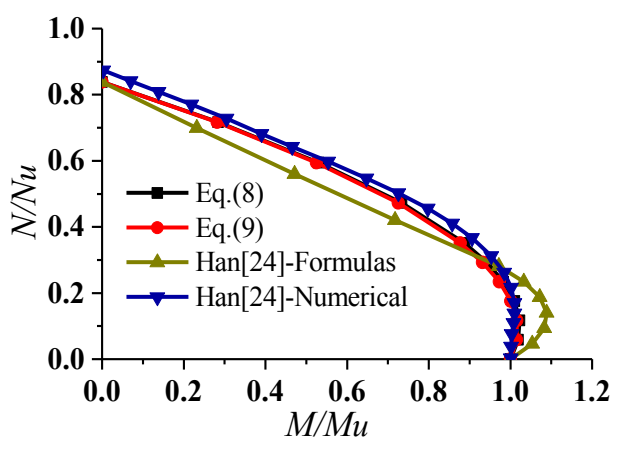

b) $\lambda=40$ 


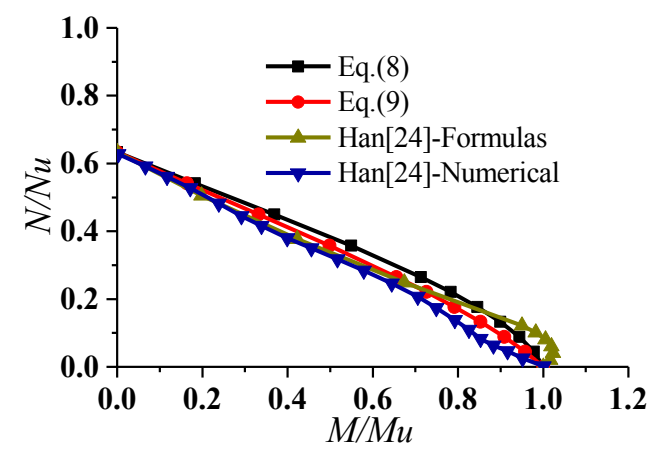

c) $\lambda=80$

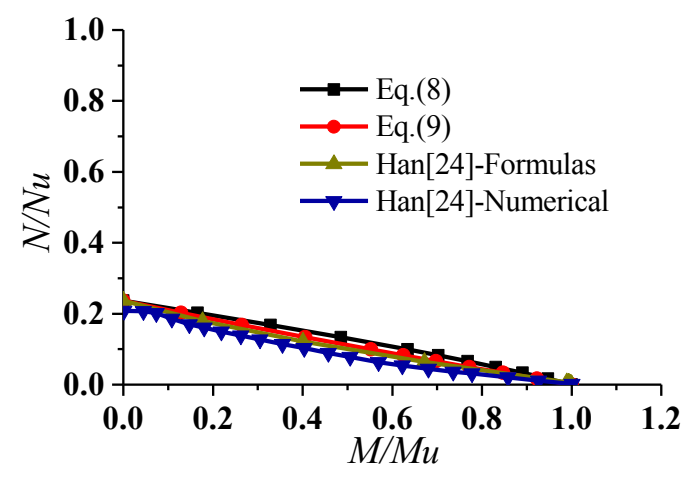

d) $\lambda=160$

Figure 6 N-M interaction curves of circular CFST columns with different slenderness ratios

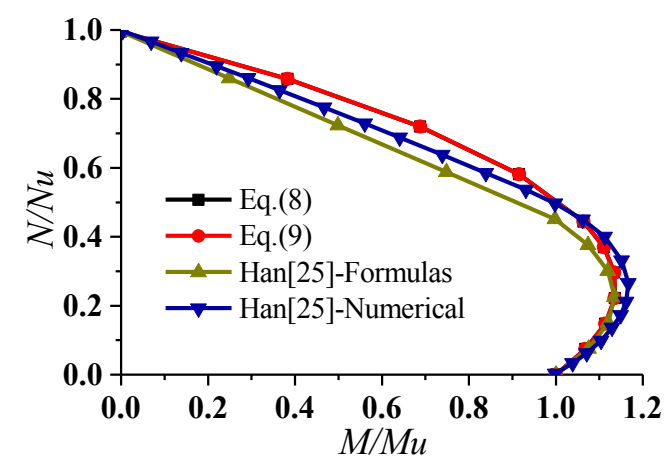

a) $\lambda=10$

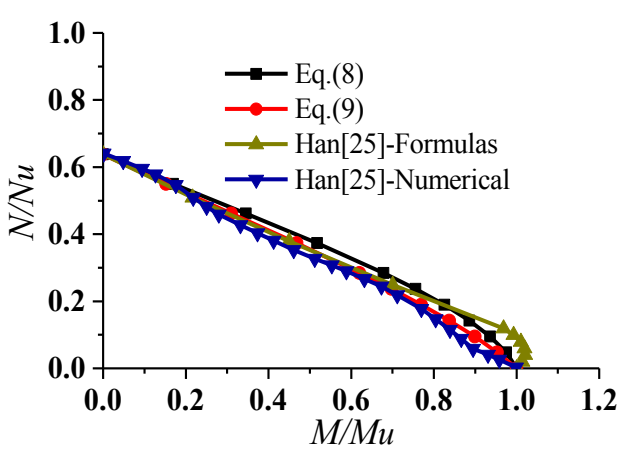

c) $\lambda=80$

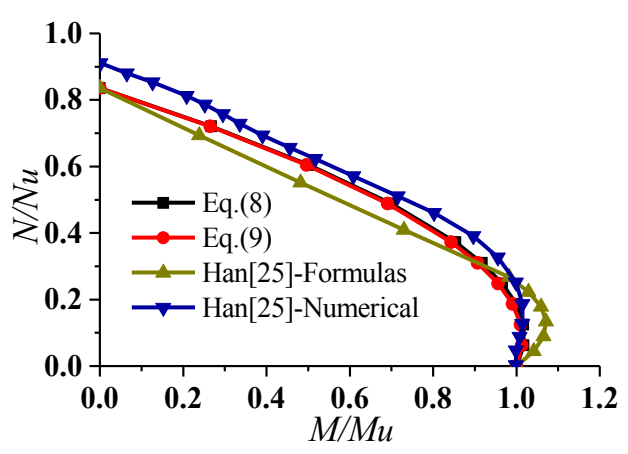

b) $\lambda=40$

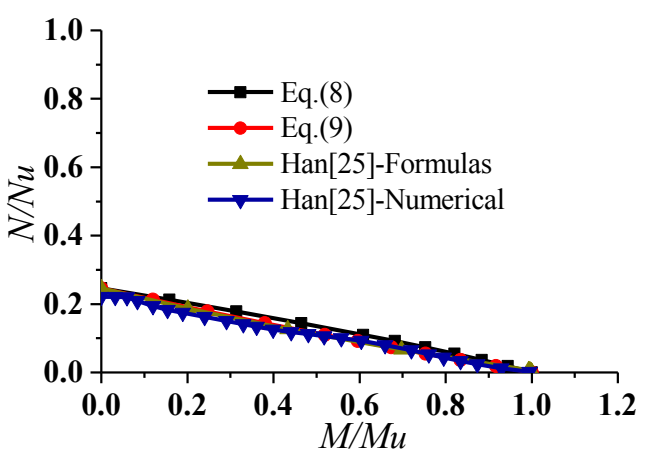

d) $\lambda=160$

Figure 7. N-M interaction curves of square CFST columns with different slenderness ratios

\subsection{N-M interaction equation of long CFST columns under elevated temperature}

In this section, the N-M equation developed in the previous section for CFST columns under room temperature is extended to include columns under elevated temperature.

Based on Eurocode 4, the authors, in their previous work ${ }^{[10]}$, used average temperature of a CFST section in the calculation of ultimate axial load of the section under fire, i.e.,

$$
N_{0, T}=A_{c} \bar{f}_{c, \bar{T}_{c}}+A_{s} f_{y, \bar{T}_{s}}
$$

where $f_{y, \bar{T}_{s}}$ is the equivalent strength of steel at average temperature $\bar{T}_{s} ; \bar{f}_{c, \bar{T}_{c}}$ is the equivalent compressive cylinder strength of concrete at average temperature $\bar{T}_{c}$, and they are, respectively ${ }^{[10]}$ :

$$
\bar{f}_{c, \bar{T}_{c}}=\bar{k}_{c, T}\left(\bar{T}_{c}\right) f_{c}^{\prime}
$$




$$
f_{y, \bar{T}_{s}}=k_{s, T}\left(\bar{T}_{s}\right) f_{y}
$$

In Eq.(11), $\bar{k}_{c, T}$ denotes the equivalent reduction factor of concrete strength as a function of average temperature which can be calculated by ${ }^{[10]}$ :

$$
\bar{k}_{c, T}\left(\bar{T}_{c}\right)=1-\frac{\bar{T}_{c}-20}{918}, 0 \leq \bar{k}_{c, T} \leq 1
$$

In Eq.(12), $k_{s, T}$ denotes the reduction factor of steel strength, also, as a function of average temperature. Eurocode $4^{[4]}$ and Lie (1993) ${ }^{[18]}$ provide tables and piecewise equations for the reduction factors of steel strength $k_{s, T}$ and elastic modulus $k_{E s, T}$ under elevated temperature. For the convenience of the following calculations and design applications using Eurocode 4 and Chinese Design Codes (GB 50936-2014), two sets of formulas are proposed through curves fitting of the discrete points from Eurocode $4^{[4]}$ and Lie $(1993)^{[18]}$, as shown in Fig. 8. Thus, the reduction factors of steel strength and elastic modulus of Eurocode $4^{[4]}$ and Lie $(1993)^{[18]}$ can be calculated, respectively, by the following new formulas, i.e.,

$$
\begin{aligned}
& k_{s, T}\left(\bar{T}_{s}\right)=\frac{f_{y, \bar{T}_{s}}}{f_{y}}=\left\{\begin{array}{cc}
1 & 20^{\circ} C \leq \bar{T}_{s} \leq 400^{\circ} C \\
e^{-\left(\frac{\bar{T}_{s}-400}{240}\right)^{1.5}} & 400^{\circ} C<\bar{T}_{s} \leq 1200^{\circ} C
\end{array}\right. \\
& k_{E s, T}\left(\bar{T}_{s}\right)=\frac{E_{s, \bar{T}_{s}}}{E_{s}}=e^{-\left(\frac{\bar{T}_{s}-20}{560}\right)^{2.5}}, \quad 20^{\circ} C \leq \bar{T}_{s} \leq 1200^{\circ} C
\end{aligned}
$$

for Eurocode 4, and

$$
\begin{aligned}
& k_{s, T}\left(\bar{T}_{s}\right)=\frac{f_{y, \bar{T}_{s}}}{f_{y}}=e^{-\left(\frac{\bar{T}_{s}-20}{601}\right)^{2.5}}, \quad 20^{\circ} C<\bar{T}_{s} \leq 1200^{\circ} C \\
& k_{E s, T}\left(\bar{T}_{s}\right)=\frac{E_{s, \bar{T}_{s}}}{E_{s}}=e^{-\left(\frac{\bar{T}_{s}-20}{652}\right)^{3}}, \quad 20^{\circ} C<\bar{T}_{s} \leq 1200^{\circ} \mathrm{C}
\end{aligned}
$$

for Lie's experimental results, where $\bar{T}_{s}$ is the average temperature of steel tube. More details of the average temperature approach can be found in $\mathrm{Yu}$, et al ${ }^{[10]}$.

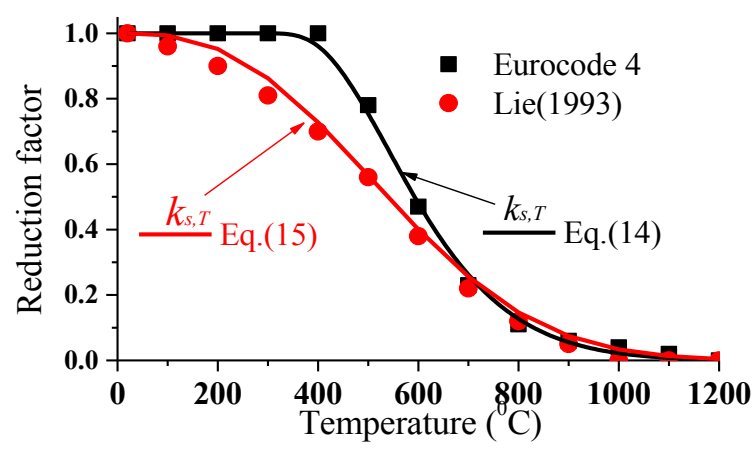

a) Strength

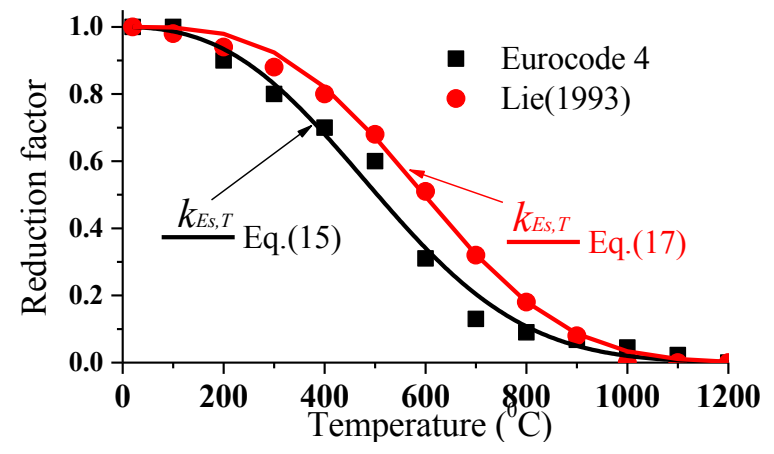

b) Elastic modulus

Figure 8. Reduction factors of strength and elastic modulus for steel under elevated temperature

For a slender column, the Euler buckling load is given by: 


$$
N_{c r, T}=\frac{\pi^{2}(E I)_{s c, T}}{L_{0}^{2}}
$$

where $(E I)_{s c, T}$ is the effective flexural stiffness under fire, $(E I)_{s c, T}=\bar{E}_{c, \bar{T}_{c}} I_{c}+E_{s, \bar{T}_{s}} I_{s} . E_{s, \bar{T}_{s}}$ is the elastic modulus of steel at average temperature $\bar{T}_{s}$, which can be calculated by Eq.(15) or Eq.(17); $\bar{E}_{c, \bar{T}_{c}}$ is the equivalent elastic modulus of concrete at average temperature $\bar{T}_{c}$, which can be calculated by ${ }^{[10]}$ :

$$
\bar{E}_{c, \bar{T}_{c}}=\bar{k}_{E c, T}\left(\bar{T}_{c}\right) E_{c}
$$

In Eq.(19), $\bar{k}_{E c, T}$ denotes the reduction factor of concrete elastic modulus as a function of average temperature, which is calculated by ${ }^{[10]}$ :

$$
\bar{k}_{E c, T}\left(\bar{T}_{c}\right)=e^{-\frac{\bar{T}_{c}-20}{211}}
$$

According to Eurocode 4, the reduction factor using the buckling curve ' $c$ ' is:

$$
\varphi_{s c, T}=\frac{1}{\Phi+\sqrt{\Phi^{2}-\bar{\lambda}_{s c, T}^{2}}} \leq 1.0
$$

where $\Phi=0.5\left[\bar{\lambda}_{s c, T}{ }^{2}+\alpha\left(\bar{\lambda}_{s c, T}-0.2\right)+1\right] ; \bar{\lambda}_{s c, T}$ is the non-dimensional slenderness ratio under fire and is given by $\bar{\lambda}_{s c, T}=\sqrt{N_{0, T} / N_{c r, T}} ; \alpha$ is the imperfection factor and, for buckling curve 'c', $\alpha$ is 0.49 .

The authors also proposed a unified formula ${ }^{[26]}$ for CFST columns subjected to pure bending and elevated temperature, by which the bending capacity of a CFST section can be calculated by:

$$
M_{u, T}=\left(1-\frac{1}{4} \frac{\xi_{T}}{\xi_{T}+1}\right) f_{y, \bar{T}_{s}} A_{s} \bar{R}
$$

where $\xi_{T}$ is the confining coefficient at elevated temperature, i.e., $\xi_{T}=A_{s} f_{y, \bar{T}_{s}} / A_{c} \bar{f}_{c k, \bar{T}_{c}} ; \bar{R}$ is the radius of a circular section or the radius of an equivalent circular section converted from a polygon.

Hence, after considering $N_{0, T}, M_{u, T}$ and $\varphi_{s c, T}$ from, respectively, Eqs.(10), (22) and (21) and introducing them into Eq.(9), the unified N-M interaction equation for CFST columns under fire is written as:

$$
\frac{\beta_{m} M}{M_{u, T}}=\left(1-\frac{N}{\varphi_{s c, T} N_{0, T}}\right)\left(1-\frac{\varphi_{s c, T} N}{N_{0 t, T}}\right)\left(1-\frac{\varphi_{s c, T} N}{N_{c r, T}}\right)
$$

Eq.(23) is a simple and explicit N-M interaction equation that is applicable to a range of section profiles, including solid, hollow, circular, polygonal, and also for short and long columns. The proposed equation can be applied (but may not be limited) to predict load bearing capacity and fire resistance of CFST columns under combined compression and bending, when the following conditions are satisfied: (a) Fire resistance time: $\mathrm{t} \leq 4 \mathrm{~h}$; (b) Hollow ratio is $0 \leq \psi \leq 0.65$; (c) Normal weight plain concrete: C30-C80 and structural steel: Q235-Q460.

\section{Experimental verifications}

\subsection{Validation of the unified N-M interaction equation for CFST columns under room temperature}


Experimental results of solid CFST columns with circular and rectangular sections under combined loads at room temperature from other researchers are used here to verify the accuracy and applicability of Eq.(23) used for columns under room temperature. Tables 3 and 4 summarise the test results from [26]-[49] and compare the respective average ultimate compressive loads with those predicted from Eq.(23). The error analyses of the comparisons are shown in Fig. 9 where all the 98 circular members and 266 square members are included. For circular members, the average ratio and coefficient of variation of the test results, $N_{\mathrm{e}}$, to the predictions, $N_{\mathrm{c}}$, are 0.921 and 0.148 , respectively. For the rectangular members, they are respectively 0.977 and 0.160 . The overall average of the ratios for both sections is 0.962 . In Tables 3 and 4, $e$ is loading eccentricity and $r$ denotes the radius of a circular section or half length of the side parallel to the eccentricity of a rectangular section.

Table 3 Comparisons of formula predictions and experimental results for circular CFST at room temperature

\begin{tabular}{|c|c|c|c|c|c|c|c|c|c|c|c|}
\hline \multirow[b]{2}{*}{ NO. } & \multirow[b]{2}{*}{ Ref. } & \multicolumn{3}{|c|}{ Geometric parameters } & \multicolumn{3}{|c|}{ Material } & \multirow{2}{*}{$\begin{array}{c}\text { Quantity } \\
n\end{array}$} & \multicolumn{3}{|c|}{ Comparisons } \\
\hline & & $D / t$ & $\lambda$ & $e / r$ & $\begin{array}{c}f_{\mathrm{y}} \\
/ \mathrm{Mpa}\end{array}$ & $\begin{array}{c}f_{\mathrm{c}}^{\prime} \\
/ \mathrm{Mpa}\end{array}$ & $\begin{array}{c}f_{\mathrm{cu}} \\
/ \mathrm{Mpa}\end{array}$ & & $N_{\mathrm{e}} / N_{\mathrm{c}}$ & $\begin{array}{c}\text { Average } \\
\mu\end{array}$ & $\begin{array}{l}\text { coefficient } \\
\text { of variation }\end{array}$ \\
\hline 1 & {$[27]$} & 33.2 & $12.2 \sim 84.2$ & $0 \sim 1.20$ & $248.9 \sim 329.3$ & - & $34.7 \sim 51.2$ & 51 & $0.690 \sim 1.155$ & 0.880 & 0.152 \\
\hline 2 & [28] & 33.2 & $16.0 \sim 48.0$ & $0.24 \sim 1.20$ & $277.3 \sim 313.6$ & - & 51.4 & 18 & $0.915 \sim 1.120$ & 1.028 & 0.055 \\
\hline 3 & [29] & 22.5 & $16.3 \sim 41.8$ & $0 \sim 1.18$ & 360.0 & - & 88.5 & 12 & $0.604 \sim 1.402$ & 0.896 & 0.219 \\
\hline 4 & [30] & $24.0 \sim 28.3$ & $14.0 \sim 60.0$ & $0.20 \sim 0.60$ & $352.0 \sim 358.0$ & - & $97.5 \sim 107.0$ & 8 & $0.899 \sim 1.084$ & 0.982 & 0.056 \\
\hline 5 & [31] & 63.5 & $31.8 \sim 91.4$ & $0.24 \sim 0.71$ & 218.0 & 67.4 & - & 9 & $0.813 \sim 1.047$ & 0.923 & 0.073 \\
\hline Total & - & $22.5 \sim 63.5$ & $12.2 \sim 91.4$ & $0 \sim 1.20$ & $218.0 \sim 360.0$ & 67.4 & $34.7 \sim 107.0$ & 98 & $0.604 \sim 1.402$ & 0.921 & 0.148 \\
\hline
\end{tabular}

Table 4 Comparison of formula predictions and experiments results for rectangular CFST at room temperature

\begin{tabular}{|c|c|c|c|c|c|c|c|c|c|c|c|}
\hline \multirow[b]{2}{*}{ NO. } & \multirow[b]{2}{*}{ Ref. } & \multicolumn{3}{|c|}{ Geometric parameters } & \multicolumn{3}{|c|}{ Material } & \multirow{2}{*}{$\begin{array}{c}\text { Quantity } \\
n\end{array}$} & \multicolumn{3}{|c|}{ Comparison result } \\
\hline & & $B / t$ & $\lambda$ & $e / r$ & $\begin{array}{c}f_{\mathrm{y}} \\
/ \mathrm{Mpa}\end{array}$ & $\begin{array}{c}f_{\mathrm{c}}^{\prime} \\
/ \mathrm{Mpa}\end{array}$ & $\begin{array}{c}f_{\mathrm{cu}} \\
/ \mathrm{Mpa}\end{array}$ & & $N_{\mathrm{e}} / N_{\mathrm{c}}$ & $\begin{array}{c}\text { Average } \\
\mu\end{array}$ & $\begin{array}{l}\text { coefficient } \\
\text { of variation }\end{array}$ \\
\hline 1 & {$[32]$} & $50.0 \sim 60.0$ & 10.4 & $0 \sim 0.40$ & 324.4 & - & 52.6 & 5 & $1.089 \sim 1.256$ & 1.186 & 0.057 \\
\hline 2 & {$[33]$} & 24.0 & 90.1 & $0 \sim 1.00$ & $384.7 \sim 386.3$ & $34.0 \sim 37.4$ & - & 3 & $0.762 \sim 0.890$ & 0.842 & 0.068 \\
\hline 3 & {$[34]$} & $21.7 \sim 25.0$ & $81.8 \sim 94.3$ & 0.10 & $350.0 \sim 370.0$ & $51.8 \sim 78.6$ & - & 4 & $0.967 \sim 1.104$ & 1.055 & 0.050 \\
\hline 4 & [35] & $34.7 \sim 54.7$ & $59.1 \sim 93.3$ & $0.19 \sim 0.24$ & 269.0 & 65.0 & - & 3 & $1.206 \sim 1.649$ & 1.413 & 0.129 \\
\hline 5 & {$[36]$} & 64.0 & $20.6 \sim 40.1$ & $0 \sim 0.63$ & 230.0 & - & $47.6 \sim 50$ & 6 & $1.022 \sim 1.206$ & 1.104 & 0.064 \\
\hline 6 & {$[37]$} & $19.2 \sim 25.0$ & $13.9 \sim 50.0$ & $0.33 \sim 1.00$ & $282.0 \sim 314.0$ & - & $45.3 \sim 85.2$ & 15 & $0.795 \sim 1.169$ & 0.977 & 0.097 \\
\hline 7 & [38] & 40.0 & $20.6 \sim 40.1$ & $0.31 \sim 0.63$ & 316.0 & - & 65.7 & 4 & $0.948 \sim 1.049$ & 1.013 & 0.039 \\
\hline 8 & {$[39]$} & $30.9 \sim 51.7$ & $25.3 \sim 72.4$ & $0.28 \sim 0.58$ & $316.6 \sim 319.3$ & - & 89.4 & 8 & $0.966 \sim 1.210$ & 1.110 & 0.068 \\
\hline 9 & {$[40]$} & $23.5 \sim 51.3$ & $10.4 \sim 23.7$ & $0.30 \sim 6.16$ & $194.0 \sim 339.1$ & - & $27.9 \sim 60.3$ & 43 & $0.681 \sim 1.157$ & 0.901 & 0.094 \\
\hline 10 & [41] & $26.5 \sim 47.7$ & 13.6 & $0.26 \sim 9.17$ & $330.7 \sim 484.4$ & - & $43.2 \sim 67.2$ & 16 & $0.862 \sim 0.920$ & 0.890 & 0.019 \\
\hline 11 & {$[42]$} & $20.5 \sim 36.5$ & $45.0 \sim 75.1$ & $0.21 \sim 0.86$ & $321.1 \sim 330.1$ & - & $28.1 \sim 54.9$ & 21 & $0.837 \sim 1.010$ & 0.933 & 0.051 \\
\hline 12 & {$[43]$} & $49.1 \sim 135.8$ & $10.4 \sim 41.6$ & $0 \sim 0.32$ & 340.1 & - & 23.1 & 35 & $0.608 \sim 1.036$ & 0.852 & 0.147 \\
\hline 13 & {$[44]$} & 66.7 & 40 & $0 \sim 0.30$ & 303.5 & - & 58.5 & 10 & $0.908 \sim 1.117$ & 1.009 & 0.067 \\
\hline 14 & {$[45]$} & $17.8 \sim 50.0$ & $13.8 \sim 59.1$ & $0 \sim 1.00$ & $242.0 \sim 320.0$ & - & $32.4 \sim 42.6$ & 16 & $0.790 \sim 1.011$ & 0.923 & 0.066 \\
\hline 15 & {$[46]$} & $36.3 \sim 69.4$ & $25.0 \sim 50.7$ & $0.23 \sim 0.82$ & $316.6 \sim 319.3$ & - & 89.4 & 8 & $1.057 \sim 1.460$ & 1.257 & 0.089 \\
\hline 16 & {$[47]$} & 73.3 & $12.4 \sim 45.5$ & $0 \sim 0.55$ & 327.0 & - & $103 \sim 112$ & 6 & $1.025 \sim 1.228$ & 1.165 & 0.048 \\
\hline 17 & {$[48]$} & $20.3 \sim 24.0$ & $36.6 \sim 127.3$ & $0.13 \sim 1.00$ & $313.0 \sim 386.0$ & - & $34.1 \sim 46.8$ & 13 & $0.622 \sim 1.011$ & 0.796 & 0.112 \\
\hline
\end{tabular}




\begin{tabular}{c|c|c|c|c|c|c|c|c|c|c|c}
\hline 18 & {$[49]$} & $33.3 \sim 56.6$ & $34.6 \sim 52.0$ & $0.61 \sim 11.09$ & 340.0 & - & $16.8 \sim 51.2$ & 30 & $0.885 \sim 1.385$ & 1.101 & 0.128 \\
\hline 19 & {$[50]$} & 52.6 & 9.0 & $0 \sim 1.00$ & 340 & - & 36.0 & 10 & $1.053 \sim 1.159$ & 1.118 & 0.032 \\
\hline Total & - & $17.8 \sim 135.8$ & $9.0 \sim 127.3$ & $0 \sim 11.09$ & $194.0 \sim 484.4$ & $34.0 \sim 78.6$ & $16.8 \sim 112$ & 256 & $0.608 \sim 1.649$ & 0.977 & 0.160 \\
\hline
\end{tabular}

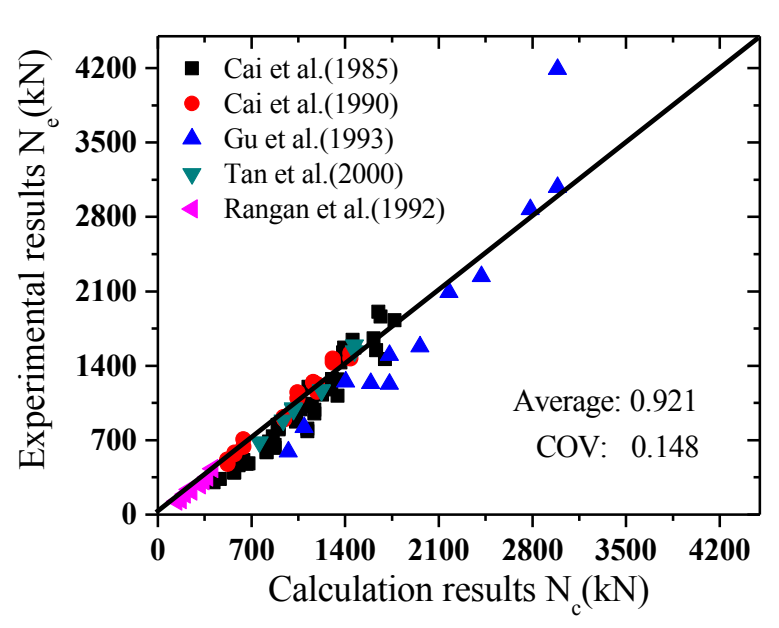

a) Circular CFST

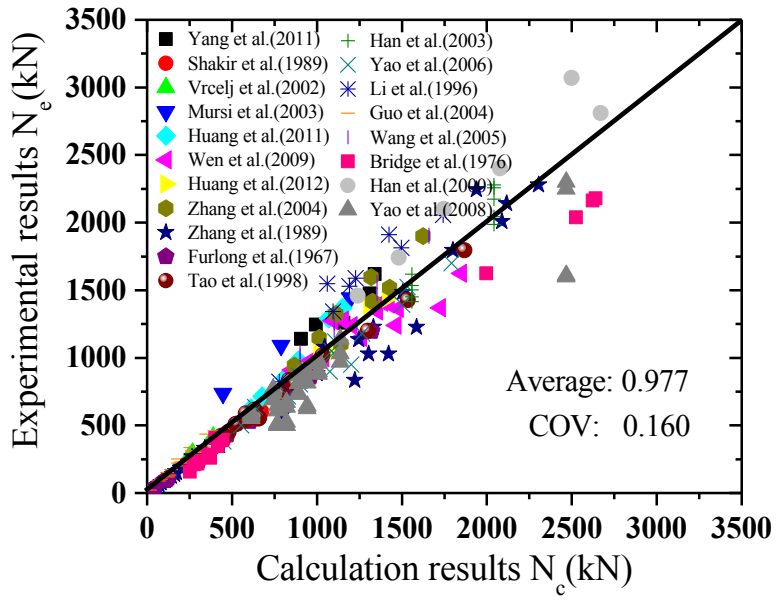

b) Rectangular CFST

Figure 9 Comparison of the unified formula with the test results

\subsection{Validation of the unified N-M interaction equation for CFST columns under elevated temperature}

To verify the applicability of Eq.(23) under elevated temperature, Table 5 and Figure 10 present comparisons between Eq.(23) and the experimental results ${ }^{[7,8,51-52,54]}$ or finite element analysis results ${ }^{[53,55]}$ carried out by other researchers on circular and rectangular CFST sections subjected to eccentric compression and fire (ISO-834). Two sets of compressive bearing capacities, $N_{\mathrm{c} 1}$ and $N_{\mathrm{c} 2}$ are predicted from Eq. (23), respectively, using the reduction factors of steel strength and elastic modulus proposed based on Eurocode $4^{[4]}$, i.e., using Eq.(14) and Eq.(15), and the ones from Lie's (1993) ${ }^{[18]}$ results, i.e., Eq.(16) and Eq.(17), the latter is adopted by GB 50936-2014 ${ }^{[19]}$.

Table 5 Comparisons with experimental or FEA results of circular and rectangular CFST under fire

\begin{tabular}{|c|c|c|c|c|c|c|c|c|c|c|c|c|c|c|}
\hline \multirow{3}{*}{ Type } & \multirow{3}{*}{ Ref. } & \multicolumn{2}{|r|}{ Serial } & \multicolumn{3}{|c|}{ Geometric parameters } & \multicolumn{3}{|c|}{ Material } & \multirow{3}{*}{$\begin{array}{c}\mathrm{E}_{\mathrm{cc}} \\
e \\
e \\
/ \mathrm{mm}\end{array}$} & \multirow{3}{*}{$\begin{array}{c}\text { Fire time } \\
T \\
T \\
/ \mathrm{min}\end{array}$} & \multicolumn{3}{|c|}{ Load } \\
\hline & & \multirow[t]{2}{*}{ NO. } & \multirow[t]{2}{*}{ Numbering } & $\begin{array}{c}\text { Length of } \\
\text { side }\end{array}$ & Thickness & Height & \multirow{2}{*}{$\begin{array}{c}f_{\mathrm{y}} \\
/ \mathrm{Mpa}\end{array}$} & \multirow{2}{*}{$\begin{array}{c}f_{\mathrm{c}}^{\prime} \\
/ \mathrm{Mpa}\end{array}$} & \multirow{2}{*}{$\begin{array}{l}f_{\mathrm{cu}} \\
/ \mathrm{Mpa}\end{array}$} & & & \multirow{2}{*}{$\begin{array}{c}N_{\mathrm{e}}\left(N_{\mathrm{FEA}}\right) \\
/ \mathrm{kN}\end{array}$} & \multirow{2}{*}{$\begin{array}{l}N_{\mathrm{cl}} \\
/ \mathrm{kN}\end{array}$} & \multirow{2}{*}{$\begin{array}{l}N_{\mathrm{c} 2} \\
/ \mathrm{kN}\end{array}$} \\
\hline & & & & $D(B) / \mathrm{mm}$ & $t / \mathrm{mm}$ & $L / \mathrm{mm}$ & & & & & & & & \\
\hline \multirow{9}{*}{$\begin{array}{r}\text { Circular } \\
\text { CFST }\end{array}$} & {$[51]$} & 1 & $\mathrm{C}-16$ & 219.1 & 8.18 & 3810 & 350 & 31.9 & - & 34 & 33 & 525 & 412.5 & 489.2 \\
\hline & \multirow{8}{*}[52]{} & 2 & C159-6-3-30-20-20 & 159 & 6 & 3180 & 332.03 & 35.83 & - & 20 & 32 & 169.0 & 222.3 & 266.1 \\
\hline & & 3 & C159-6-3-30-20-40 & 159 & 6 & 3180 & 332.03 & 42.17 & - & 20 & 16 & 337.0 & 606.9 & 573.2 \\
\hline & & 4 & C159-6-3-90-20-20 & 159 & 6 & 3180 & 332.03 & 73.70 & - & 20 & 34 & 272.0 & 241.3 & 304.6 \\
\hline & & 5 & C159-6-3-90-20-40 & 159 & 6 & 3180 & 343.63 & 74.64 & - & 20 & 11 & 544.0 & 899.5 & 845.8 \\
\hline & & 6 & C159-6-3-30-50-20 & 159 & 6 & 3180 & 343.63 & 30.50 & - & 50 & 29 & 126.4 & 188.2 & 214.8 \\
\hline & & 7 & C159-6-3-30-50-40 & 159 & 6 & 3180 & 365.65 & 38.25 & - & 50 & 23 & 252.8 & 295.6 & 309.3 \\
\hline & & 8 & C159-6-3-90-50-20 & 159 & 6 & 3180 & 365.65 & 79.13 & - & 50 & 30 & 194.0 & 219.4 & 261.9 \\
\hline & & 9 & C159-6-3-90-50-40 & 159 & 6 & 3180 & 365.65 & 98.32 & - & 50 & 16 & 388.0 & 560.6 & 539.5 \\
\hline
\end{tabular}




\begin{tabular}{|c|c|c|c|c|c|c|c|c|c|c|c|c|c|c|}
\hline & & 10 & $\mathrm{C} 1-2$ & 478 & 8 & 3810 & 432.7 & - & 41.3 & 71.7 & 32 & 2200.0 & 3056.8 & 3157.4 \\
\hline & {$[8]$} & 11 & $\mathrm{C} 2-1$ & 219 & 5 & 3810 & 432.7 & - & 41.3 & 32.9 & 17 & 450.0 & 678.6 & 661.7 \\
\hline & & 12 & $\mathrm{C} 2-2$ & 219 & 5 & 3810 & 432.7 & - & 41.3 & 65.7 & 18 & 300.0 & 497.8 & 481.3 \\
\hline & & 13 & C3-2 & 219 & 4.6 & 3810 & 381 & - & 68.8 & 42 & 7 & 1007.0 & 1133.3 & 1099.7 \\
\hline & & 14 & S2 & 159 & 6 & 3180 & 275 & 30 & - & 20.0 & 21.5 & 237.4 & 363.9 & 372.1 \\
\hline & & 15 & S3 & 159 & 6 & 3180 & 275 & 30 & - & 50.0 & 21.4 & 192.8 & 272.9 & 273.9 \\
\hline & {$[53$} & 16 & S4 & 159 & 6 & 3180 & 275 & 30 & - & 80.0 & 21.0 & 160.8 & 220.7 & 215.4 \\
\hline & & 17 & S9 & 159 & 6 & 3180 & 275 & 60 & - & 20.0 & 23.3 & 312.0 & 383.6 & 418.0 \\
\hline & & 18 & $\mathrm{~S} 10$ & 159 & 6 & 3180 & 430 & 60 & - & 20.0 & 20.3 & 365.4 & 535.2 & 559.3 \\
\hline & & 19 & S11 & 159 & 6 & 3180 & 630 & 60 & - & 20.0 & 19.0 & 445.8 & 669.3 & 691.9 \\
\hline \multirow{21}{*}{$\begin{array}{l}\text { Rectangular } \\
\text { CFST }\end{array}$} & \multirow{2}{*}{ [7] } & 20 & $\mathrm{R}-2$ & $300 \times 200$ & 7.96 & 3810 & 340.6 & - & 49 & 22.5 & 24 & 2233.0 & 1541.6 & 1571.7 \\
\hline & & 21 & $\mathrm{R}-4$ & $300 \times 150$ & 7.96 & 3810 & 340.6 & - & 49 & 22.5 & 20 & 1853.0 & 1368.8 & 1336.4 \\
\hline & \multirow{2}{*}{ [54] } & 22 & RF-2 & $300 \times 200$ & 7.96 & 3810 & 340.6 & - & 49 & 22.5 & 21 & 2233.0 & 1795.8 & 1752.5 \\
\hline & & 23 & RF-6 & $300 \times 150$ & 7.96 & 3810 & 340.6 & - & 49 & 22.5 & 18 & 1853.0 & 1535.7 & 1449.4 \\
\hline & \multirow{17}{*}[55]{} & 24 & 2 & $300 \times 200$ & 3 & 1500 & 235 & - & 30 & 37.5 & 11.2 & 1246.8 & 1340.6 & 1189.9 \\
\hline & & 25 & 3 & $300 \times 200$ & 3 & 1500 & 235 & - & 30 & 45.0 & 11 & 1173.5 & 1284.2 & 1137.4 \\
\hline & & 26 & 4 & $300 \times 200$ & 3 & 1500 & 235 & - & 30 & 60.0 & 10.4 & 1034.4 & 1178.0 & 1044.3 \\
\hline & & 27 & 5 & $300 \times 200$ & 3 & 1500 & 235 & - & 30 & 75.0 & 10.1 & 946.0 & 1072.4 & 950.1 \\
\hline & & 28 & 6 & $300 \times 200$ & 3 & 1500 & 235 & - & 30 & 90.0 & 9.8 & 876.6 & 976.7 & 864.7 \\
\hline & & 29 & 7 & $300 \times 200$ & 3 & 1800 & 235 & - & 30 & 37.5 & 11.5 & 1164.5 & 1294.0 & 1151.2 \\
\hline & & 30 & 8 & $300 \times 200$ & 3 & 2100 & 235 & - & 30 & 37.5 & 12.5 & 1139.1 & 1217.2 & 1090.8 \\
\hline & & 31 & 9 & $300 \times 200$ & 3 & 2400 & 235 & - & 30 & 37.5 & 13.8 & 1110.6 & 1124.5 & 1022.7 \\
\hline & & 32 & 10 & $300 \times 200$ & 3 & 2700 & 235 & - & 30 & 37.5 & 11 & 1080.0 & 1202.5 & 1079.6 \\
\hline & & 33 & 11 & $300 \times 200$ & 3 & 3000 & 235 & - & 30 & 37.5 & 8 & 1047.8 & 1215.3 & 1142.4 \\
\hline & & 34 & 12 & $300 \times 200$ & 3 & 3300 & 235 & - & 30 & 37.5 & 6.2 & 1014.0 & 1206.1 & 1163.1 \\
\hline & & 35 & 13 & $300 \times 200$ & 3 & 3600 & 235 & - & 30 & 37.5 & 5 & 979.2 & 1188.4 & 1162.2 \\
\hline & & 36 & 18 & $300 \times 200$ & 3 & 1500 & 235 & - & 30 & 37.5 & 22.5 & 809.6 & 890.6 & 879.1 \\
\hline & & 37 & 19 & $300 \times 200$ & 3 & 1500 & 235 & - & 30 & 37.5 & 19.1 & 890.6 & 1001.5 & 958.3 \\
\hline & & 38 & 20 & $300 \times 200$ & 3 & 1500 & 235 & - & 30 & 37.5 & 16.3 & 971.5 & 1113.9 & 1032.9 \\
\hline & & 39 & 21 & $300 \times 200$ & 3 & 1500 & 235 & - & 30 & 37.5 & 13.7 & 1052.5 & 1232.6 & 1109.9 \\
\hline & & 40 & 22 & $300 \times 200$ & 3 & 1500 & 235 & - & 30 & 37.5 & 11.5 & 1133.4 & 1329.7 & 1180.1 \\
\hline
\end{tabular}




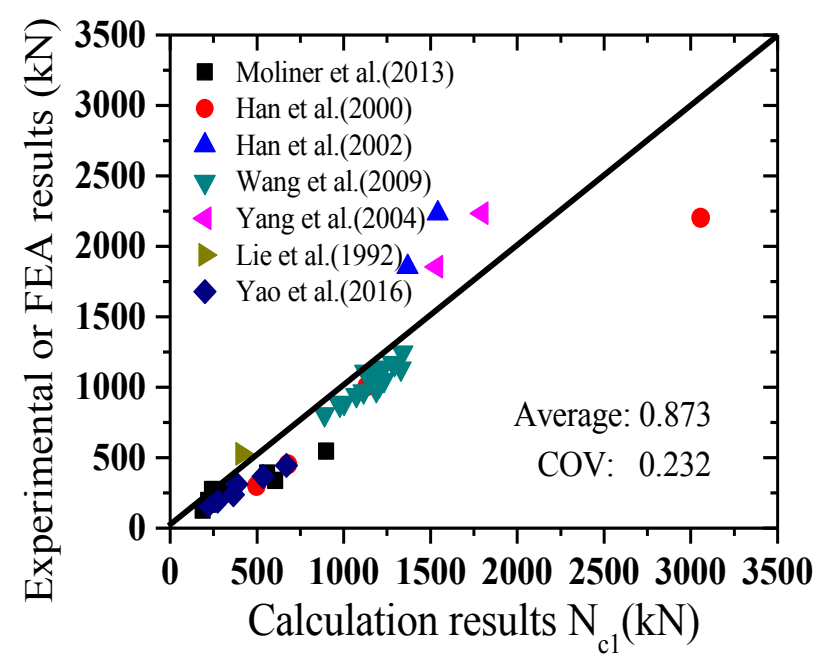

a) Reduction factors based on Eurocode 4

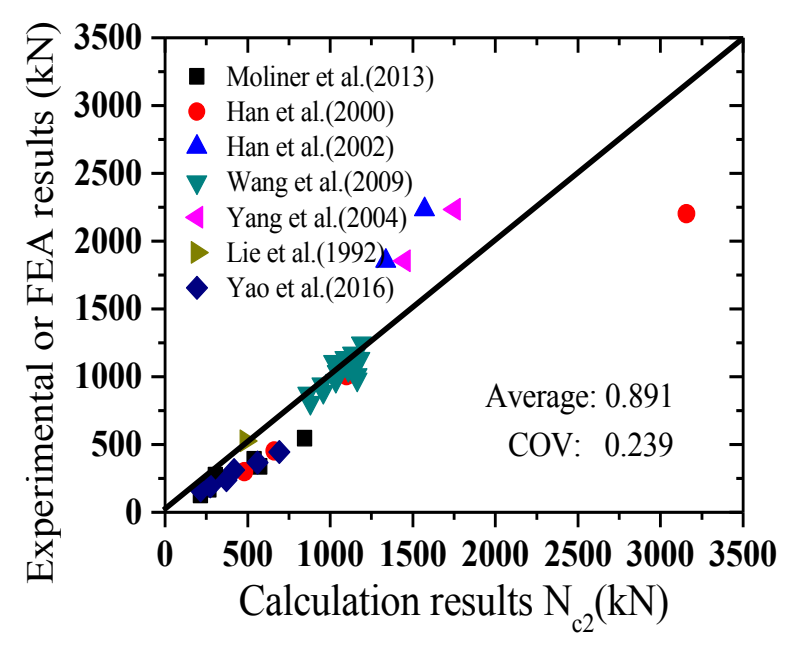

b) Reduction factors from GB 50936-2014

Figure 10. Comparisons of formula predictions with experimental or FEA results

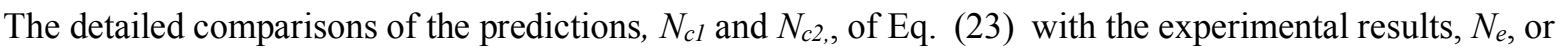
FEA results, $N_{\mathrm{FEA}}$, can be seen form Figure 10, where 19 circular members and 21 rectangular members are included. Using the steel strength reduction factors recommended by Eurocode 4, the average ratio and coefficient of variation of the experimental or FEA results to the predictions are 0.873 and 0.232 , respectively. When the reduction factors recommended by Lie (1993) ${ }^{[18]}$ and GB 50936-2014[19], the respective average ratio and coefficient of variation are 0.891 and 0.239 . Although the selection of reduction factors has some influences on the calculation results, the discrepancies are generally within an acceptable range and all the predictions, i.e., $N_{c l}$ and $N_{c 2}$, are comparable with the test or FEA results.

The unified N-M interaction equation are also compared with simplified expressions proposed by $\operatorname{Han}^{[7,8]}$ for calculating fire resistance of CFST columns. The average ratio and coefficient of variation of the experimental or FEA results to the prediction calculated by Han's formulas are 0.858 and 0.212 , respectively, which has similar calculation accuracy to the results offered by Eq. (23). However, the unified N-M interaction equation proposed in this paper is much simpler and can apply to CFST columns under both room and elevated temperatures.

It is worthwhile to note that the proposed unified formula covers a wider range of section profiles, while most published formulas work only for a specific section or loading case. In most of the cases we considered validations for sections that have either the most or the least number of sides commonly used in practical design, e.g., circular section (infinite number of sides) and rectangular sections (4 sides). The validations have shown that the predictions of Eq. (23) for 4 sided sections are less accurate than for the circular ones, which suggests that more accurate predictions are expected from sections having more sides. The comparisons shown in Figure 5 for octagonal sections have demonstrated this expectation.

\section{Concluding remarks}

A novel, simple and unified explicit N-M interaction equation for predicting load bearing capacity and fire resistance of CFST columns under combined compression and bending has been developed in this paper. The 
equations can be applied to a range of section profiles, including solid, hollow, circular, polygonal, and also for short and long columns. Only global stability was considered in the equation.

The new equation was validated against available eccentrically loaded short and long CFST columns with circular and rectangular cross sections subjected to room and elevated temperatures, which all demonstrated that the much simpler N-M interaction equation provided comparable or even more accurate predictions to the load bearing capacities of CFST columns under room and elevated temperatures.

Further work is needed to extend the interaction equation to include columns subjected to shear and torsional loadings. For bar-reinforced and other types of CFST columns, the applicability of the unified interaction equation needs future investigations and verifications. Reliability analysis on fire resistance of CFST columns under combined loadings is also needed.

\section{Acknowledgement}

The authors are grateful for the financial support from the National Natural Science Foundation of China (Grant No.51508425), the Natural Science Foundation of Hubei Province, China (Grant No.2015CFB171).

\section{References}

[1] Kodur VK, Lie TT. Fire Performance of Concrete-Filled Hollow Steel Columns[J]. Journal of Fire Protection Engineering, 1995,7(3):89-97.

[2] Lie TT, Kodur VKR. Fire Resistance of Steel Columns Filled with Bar-Reinforced Concrete[J]. Journal of Structural Engineering, 1996,122(1):30-36.

[3] Kodur VKR. Design Equations for Evaluating Fire Resistance of SFRC-Filled HSS Columns[J]. Journal of Structural Engineering, 1998,124(6):671-677.

[4] EN 1994-1-2:2005. Design of Composite Steel and Concrete Structures Part 1.2: General Rules, Structural Fire Design, Brussels[S]. British Standards Institution, 2005.

[5] Wang YC, Kodur VKR. An Approach for Calculating the Failure Loads of Unprotected Concrete Filled Steel Columns Exposed to Fire[J]. Structural Engineering and Mechanics, 1999,7(2):127-145.

[6] Li GQ, He JL, Han LH. Load bearing Capacity of Fire resistance of Concrete Filled Steel Tubular Columns[J]. Building Structure, 2001,31(01):60-62.(in Chinese)

[7] Han LH, Yang YF, Xu L. An Experimental Study and Calculation On the Fire Resistance of ConcreteFilled SHS and RHS Columns[J]. Journal of Constructional Steel Research, 2003,59(4):427-452.

[8] Han LH, Zhao XL, Yang YF, et al. Experimental Study and Calculation of Fire Resistance of ConcreteFilled Hollow Steel Columns[J]. Journal of Structural Engineering, 2003,129(3):346-356.

[9] Tan KH, Tang CY. Interaction Model for Unprotected Concrete Filled Steel Columns Under Standard Fire Conditions.[J]. Journal of Structural Engineering, 2004,130(9):1405-1413.

[10] Yu M, Zha XX, Ye JQ, et al. A Unified Method for Calculating Fire Resistance of Solid and Hollow Concrete-Filled Steel Tube Columns Based on Average Temperature[J]. Engineering Structures, 2014,71:12-22.

[11] Espinos A, Romero ML, Hospitaler A. Fire Design Method for Bar-Reinforced Circular and Elliptical Concrete Filled Tubular Columns.[J]. Engineering Structures, 2013,56:384-395.

[12] Espinos A, Romero ML, Hospitaler A. Simple Calculation Model for Evaluating the Fire Resistance of Unreinforced Concrete Filled Tubular Columns.[J]. Engineering Structures, 2012,42:231-244.

[13] He JL, Zhong ST. The Thickness Calculation of Fire Resisting Covering of Concrete Filled Steel Tube (CFST)[J]. Journal of Harbin University of Civil Engineering \& Architecture, 1999(05):29-33.(in Chinese)

[14] Yin J, Zha XX, Li LY. Fire Resistance of Axially Loaded Concrete Filled Steel Tube Columns[J]. Journal 
of Constructional Steel Research, 2006,65(12):701-706.

[15] Chung KS, Park SH, Choi SM. Fire Resistance of Concrete Filled Square Steel Tube Columns Subjected to Eccentric Axial Load[J]. Steel Structure, 2009(9):69-76.

[16] Wang ZH, Tan KH. Green's Function Solution for Transient Heat Conduction in Concrete-Filled CHS Subjected to Fire[J]. Engineering Structures, 2006,28(11):1574-1585.

[17] Yu M, Zha XX, Ye JQ, et al. Fire Responses and Resistance of Concrete-Filled Steel Tubular Frame Structures[J]. International Journal of Structural Stability and Dynamics, 2010,10(2):253-71.

[18] Lie TT. Structural Fire Protection: Manual of Practice, ASCE Manual and Reports On Engineering Practice, No. 78[R]. New York: American Society of Civil Engineers, 1993.

[19] GB 50936-2014. Technical Code for Concrete Filled Steel Tubular Structures[S]. Beijing: China Architecture \& Building Press, 2014.(in Chinese)

[20] Yu M, Zha XX, Ye JQ, et al. A Unified Formulation for Circle and Polygon Concrete-Filled Steel Tube Columns Under Axial Compression[J]. Engineering Structures, 2013,49:1-10.

[21] Kong FK, Evans RH. Reinforced and Prestressed Concrete[M]. 3rd ed. UK: Chapman and Hall, 1987.

[22] Chen WF, Atsuta T. Theory of Beam-Columns, Vol. I: In-Plane Behavior and Design[M]. USA: McGrawHill, Inc, 1976.

[23] EN 1994-1-1:2004. Design of Composite Steel and Concrete Structures Part 1.1: General Rules and Rules for Buildings[S]. British Standards Institution, 2004.

[24] Han LH, Yao GH, Zhao XL. Behavior and Calculation On Concrete-Filled Steel CHS (Circular Hollow Section) Beam-Columns[J]. Steel and Composite Structures, 2004,4(3):169-188.

[25] Han LH, Zhao XL, Tao Z. Tests and Mechanics Model for Concrete-Filled SHS Stub Columns, Columns and Beam-Columns[J]. Steel and Composite Structures, 2001,1(1):51-74.

[26] Yu M, Pei XY, Xu LH, et al. A Unified Formula for Calculating Bending Capacity of Solid and Hollow Concrete-Filled Steel Tubes Under Normal and Elevated Temperature[J]. Journal of Constructional Steel Research, 2018,141:216-225.

[27] Cai SH, Di XT. Behaviour and Ultimate Strength of Concrete-Filled Tube Columns under Eccentric Loading[J]. Journal of Building Structures, 1985(04):32-42.(in Chinese)

[28] Cai SH, Gu WP. Influence of Moment Distribution Diagram on Load-Carrying Capacity of Concrete-Filled Steel Tubular Columns[J]. Journal of Building Structures, 1990(05):1-8.(in Chinese)

[29] Gu WP, Cai SH, Feng W L. Behaviour and Ultimate Strength of Steel-Tube-Confined High-Strength Concrete Columns[J]. Building Science, 1993(03):8-12.(in Chinese)

[30] Tan KF, Pu XC. Behaviour and Ultimate Strength of Steel-Tube-Confined Ultra-High-Strength Concrete Long Columns[J]. Journal of Building Structures, 2000(02):12-19.(in Chinese)

[31] Rangan BV, Joyce M. Strength of Eccentrically Loaded Slender Steel Tubular Columns Filled with HighStrength Concrete[J]. ACI Structural Journal, 1992,89(6):676-681.

[32] Yang YF, Han LH. Behaviour of Concrete Filled Steel Tubular (CFST) Stub Columns Under Eccentric Partial Compression[J]. Thin-Walled Structures, 2011,49(2):379-395.

[33] Shakir-Khalil H, Zeghiche J. Experimental Behaviour of Concrete-Filled Rolled Rectangular Hollow Section Columns[J]. Struct.Eng., 1989,68(20):405-413.

[34] Vrcelj Z, Uy B. Behaviour and Design of Steel Square Hollow Sections Filled with High Strength Concrete[J]. Australian Journal of Structural Engineering, 2002,3(3):153.

[35] Mursi M, Uy B. Strength of Concrete Filled Steel Box Columns Incorporating Interaction Buckling[J]. JOURNAL OF STRUCTURAL ENGINEERING-ASCE, 2003,129(5):626-639.

[36] Huang H, Chen MC, Wan CY. Behavior of concrete-filled stiffened square steel tubes subjected to eccentric compressive load[J]. China Civil Engineering Journal, 2011,44(10).(in Chinese)

[37] Wen Y, Hao MK, Li B. Experimental research on the mechanical behavior of concrete-filled square steel tube columns subjected to eccentric compression[J]. Journal of Inner Mongolia University of Science and 
Technology, 2009(03):249-252.(in Chinese)

[38] Huang H, Chen MC, Yang C, et al. Mechanical behavior of concrete-filled square steel tubular columns subjected to eccentric loading of unequal end-moment[J]. Journal of Building Structures, 2012,33(9):5966.(in Chinese)

[39] Zhang SM, Guo LH, Wang YY, et al. Experimental research and theoretical analysis of high strength concrete-filled square hollow section steel tubes subjected to eccentric loading[J]. Journal of Building Structures, 2004(01):17-24.(in Chinese)

[40] Zhang ZG. Research on basic behavior of concrete filled square steel tubular stub under eccentric load[J]. Journal of Building Structures, 1989(06):10-20.(in Chinese)

[41] Furlong RW. Strength of Steel-Encased Concrete Beam Columns[J]. Journal of the Structural Division American Society of Civil Engineers, 1967,93:113-124.

[42] Tao Z, Wei ZB. Research on the behaviors and load bearing capacity of square concrete filled steel tubes subjected to compression-bending[J]. Industrial Construction, 1998(10):10-14.(in Chinese)

[43] Han LH, Yao GH. Influence of Concrete Compaction On the Strength of Concrete-Filled Steel RHS Columns[J]. Journal of Constructional Steel Research, 2003,59(6):751-767.

[44] Yao GH. Research on behavior of concrete-filled steel tubes subjected to complicated loading states[D]. Fuzhou University, 2006.(in Chinese)

[45] Li SP, Zou SZ, Guan G, et al. Numerical simulation of collapse of concrete-filled square steel tubular columns under eccentric compression[J]. Journal of Huazhong University of Science and Technology, 1996(05):91-94.(in Chinese)

[46] Guo LH, Zhang SH, Tian H. High strength concrete-filled RHS steel tubes subjected to eccentric loading[J]. Journal of Harbin Institute of Technology, 2004(03):297-301.(in Chinese)

[47] Wang ZB, Tao Z, Han LH. Experimental study on bearing capacity of eccentrically-loaded rectangular steel tubular columns filled with high-performance concrete[J]. Steel Construction, 2005(05):54-57.(in Chinese)

[48] Bridge RQ. Concrete Filled Steel Tubular Columns[R]. Sydney: University of Sydney, 1976.

[49] Han LH. Concrete-filled steel tubular structures[M]. Science Press, 2000.(in Chinese)

[50] Yao M, Gao J. Experiment research on the capacity of short column with concrete-filled rectangular steeltube subjected to eccentric compression[J]. Sichuan Building Science, 2008(02):41-43.(in Chinese)

[51] Lie TT, Chabot M. Experimental Studies On the Fire Resistance of Hollow Steel Columns Filled with Plain Concrete, NRC-CNRC internal report no. 611[R]. Construction National Research Council Canada, 1992.

[52] Moliner V, Espinos A, Romero ML, et al. Fire Behavior of Eccentrically Loaded Slender High Strength Concrete-Filled Tubular Columns[J]. Journal of Constructional Steel Research, 2013,83:137-146.

[53] Yao Y, Li H, Guo H, et al. Fire Resistance of Eccentrically Loaded Slender Concrete-Filled Steel Tubular Columns[J]. Thin-Walled Structures, 2016,106:102-112.

[54] Yang YF, Han LH. Fire performance and design method of concrete- filled steel rectangular hollow section columns[J]. Journal of Building Structures, 2004,25(1):25-35.(in Chinese)

[55] Wang J. The Studies on Fire Resistance Performance of Eccentrical Compressive Concrete-Filled ThinWalled Steel Tube Columns[D]. Huaqiao University2009.(in Chinese) 